HETEROCYCLES, Vol. 90, No. 1, 2015, pp. 7 - 21. @ 2015 The Japan Institute of Heterocyclic Chemistry DOI: $10.3987 / C O M-14-S(K)$ Publications

\title{
LIST OF PUBLICATION (ISAO KUWAJIMA)
}

1) T. Mukaiyama, H. Nambu, and I. Kuwajima, "Reactions of Mercuric Carboxylates with Trivalent Phosphorus Compounds", J. Org. Chem., 28, 917-920 (1963).

2) T. Mukaiyama, I. Kuwajima, and Z. Suzuki, "Novel Method for the Preparation of Acid Anhyd-rides by Means of Diphenylmercury and Tertiary Phosphines", J. Org. Chem., 28, 2024-2027 (1963).

3) I. Kuwajima and T. Mukaiyama, "A Novel Method for the Preparation of Acid Anhydrides by Means of trans-Dibenzoylethylene and Tertiary Phosphines", J. Org. Chem., 29, 1385-1388 (1964).

4) T. Mukaiyama, I. Kuwajima, and K. Ohno, "The Reactions of Benzoyl Cyanide with Trivalent Phosphorus Compounds", Bull. Chem. Soc. Jpn., 38, 1954-1957 (1965).

5) T. Mukaiyama, I. Kuwajima, and K. Mizui, "1,4-Addition Type Ring opening Polymerization of 1,3-Oxazolidine-2-thione", J. Org. Chem., 31, 32-34 (1966).

6) T. Mukaiyama, R. Yoda, and I. Kuwajima, "Reactions of Phenylisocyanate with Vinyl Ethers", Tetrahedron Lett., 6247-6249 (1966).

7) I. Kuwajima, K. Narasaka, and T. Mukaiyama, "The Reaction of Allylmercuric Iodide with Acyl Halides", Tetrahedron Lett., 4281-4284 (1967).

8) T. Mukaiyama, K. Takahashi, and I. Kuwajima, "Oxidation of Halomagnesium sec-Alkoxides to Ketones", Bull. Chem. Soc. Jpn., 41, 1491 (1968).

9) T. Mukaiyama, R. Yoda, and I. Kuwajima, "Reactions of ( $\alpha, \alpha$-Disubstituted Phenacyl) and (Carbethoxy Disubstituted Methyl)triphenylphosphonium Halides with Grignard Reagents", Tetrahedron Lett., 23-24 (1969).

10) E. J. Corey and I. Kuwajima, "Reactions of $\delta$ - and $\varepsilon$-Halo Ketones with Certain Anionic Transition Metal Complexes. A Useful Cyclization Method", J. Am. Chem. Soc., 92, 395-396 (1970).

11) E. J. Corey and I. Kuwajima, "One-Step Synthesis of $\gamma, \delta$-Unsaturated Nitriles from Allylic Halides Using Cyanomethylcopper", Tetrahedron Lett., 487-489 (1972).

12) I. Kuwajima and M. Uchida, "A New Method for the Synthesis of Olefins via $\beta$-Hydroxy Sulfoxides", Tetrahedron Lett., 649-652 (1972).

13) I. Kuwajima and Y. Kurata, "A Novel Method for the Preparation of Phenylthiomethyl Ketones", Chem. Lett., 291-292 (1972).

14) I. Kuwajima, S. Sato, and Y. Kurata, "A New Method for the Synthesis of Olefins via $\beta$-Hydroxyalkyl Phenyl Sulfides", Tetrahedron Lett., 737-739 (1972).

15) I. Kuwajima and Y. Doi, "A Convenient Preparative Method of $\gamma, \delta$-Unsaturated Esters", Tetrahedron Lett., 1163-1166 (1972).

16) I. Kuwajima and Y. Fukuda, "A New Rearrangement Reaction of 1-Chloro-2-hydroxyalkyl Phenyl Sulfoxides", Tetrahedron Lett., 327-330 (1973).

17) I. Kuwajima, H. Shinozaki, and S. Hayakawa, "A Convenient Preparative Method of $\alpha$-Chloro 
Ketones", Chem. Lett., 197-200 (1973).

18) I. Kuwajima and H. Iwasawa, "Generation of the Dianion of Phenylsulfinyl Acetone and its Reactions", Tetrahedron Lett., 107-110 (1974).

19) I. Kuwajima, K. Sugimoto, and T. Murofushi, "A Convenient Method for the Preparation of 1-Phenylthio-1,3-butadiene Derivatives", Chem. Lett., 625-626 (1974).

20) I. Kuwajima and E. Nakamura, "Quaternary Ammonium Enolates as Synthetic Intermediates. Regiospecific Monoalkylation of Ketones", J. Am. Chem. Soc., 97, 3257 (1975).

21) E. Nakamura, T. Murofushi, M. Shimizu, and I. Kuwajima, "Quaternary Ammonium Enolates as Synthetic Intermediates. Trimethylsilylacetate: A New Class of Silylating Reagent for Ketones and Alcohols", J. Am. Chem. Soc., 98, 2346-2348 (1976).

22) I. Kuwajima, T. Sato, N. Minami, and T. Abe, "An Efficient Method for the Preparation of 1,1-Bis-(trimethylsilyl)alkan-1-ol", Tetrahedron Lett., 1591-1594 (1976).

23) E. Nakamura, M. Shimizu, and I. Kuwajima, "Quaternary Ammonium Enolates as Synthetic Intermediates. Generation of Ester Enolates by the Aid of $\alpha$-Trimethylsilylesters and Quaternary Ammonium Fluoride, and their Reactions with Carbonyl Compounds", Tetrahedron Lett., 1699-1702 (1976).

24) I. Kuwajima, T. Sato, M. Arai, and N. Minami, "Regiospecific Directed Aldol Reactions of Methyl Ketones with Aldehydes", Tetrahedron Lett., 1817-1820 (1976).

25) I. Kuwajima, N. Minami, and M. Arai, "A Convenient Method for the Preparation of $\beta$-Hydroxy Esters", Tetrahedron Lett., 2253-2256 (1976).

26) E. Nakamura and I. Kuwajima, "Fluoride Catalyzed Addition of Silylacetylenes to Carbonyl Compounds", Angew. Chem. Int. Ed. Engl., 15, 498 (1976).

27) I. Kuwajima, T. Murofushi, and E. Nakamura, "Quaternary Ammonium Fluoride Catalyzed Conjugate Addition of Thiols to C=C Double Bonds", Synthesis, 602-604 (1976).

28) I. Kuwajima, T. Abe, and N. Minami, "An Efficient Method for the Preparation of Acylsilanes and $\alpha$-Haloacylsilanes", Chem. Lett., 993-994 (1976).

29) I. Kuwajima, Y. Higuchi, H. Iwasawa, and T. Sato, "Decomposition Reactions of Unsaturated $\alpha$-Phenylsulfonyl- $\alpha$-diazo Ketones", Chem. Lett., 1271-1274 (1976).

30) E. Nakamura and I. Kuwajima, "Geminal Acylation via Pinacol Rearrangement. Synthesis of Spiro[4.n] Ring System", J. Am. Chem. Soc., 99, 961-963 (1977).

31) R. Noyori, K. Yokoyama, J. Sakata, I. Kuwajima, E. Nakamura, and M. Shimizu, "Fluoride Anion Catalyzed Aldol Reaction between Enol Silyl Ethers and Carbonyl Compounds", J. Am. Chem. Soc., 99, 1265-1267 (1977).

32) I. Kuwajima, M. Arai, and T. Sato, "Reactions of Lithium Alkoxides of 1,1-Bis(trimethylsilyl)alkan-1-ols with Benzophenone. A Novel Way to Silyl Enol Ethers of Acylsilanes", J. Am. Chem. Soc., 99, 4181-4182 (1977).

33) T. Sato, M. Arai, and I. Kuwajima, "An Effective Preparative Method of $\alpha, \beta$-Unsaturated Aldehydes via $\beta$-Alkoxyacylsilanes", J. Am. Chem. Soc., 99, 5827-5828 (1977).

34) I. Kuwajima and E. Nakamura, "Generation of the trans-Enolate of Chloroacetaldehyde via a 3-Oxido Carbenoid", J. Org. Chem., 42, 346-347 (1977).

35) E. Nakamura, K. Hashimoto, and I. Kuwajima, "A Novel Ring Opening Reaction. An Improved Method for Reductive Succinoylation", J. Org. Chem., 42, 4166-4167 (1977).

36) N. Minami and I. Kuwajima, "Generation of the Enolate of Succinic Anhydride in the Presence 
of Carbonyl Compounds. A Facile Preparative Method of $\beta$-Methoxycarbonyl $\gamma$-Substituted $\gamma$-Butyrolactones", Tetrahedron Lett., 1423-1424 (1977).

37) I. Kuwajima, K. Atsumi, and I. Azegami, "Reductive Silylation Reactions of 2-Furoates", $J$. Chem. Soc., Chem. Commun., 76 (1977).

38) E. Nakamura and I. Kuwajima, "Homoenolate Anion Precursor. Reaction of Ester Homoenol Silyl Ether and Carbonyl Compounds", J. Am. Chem. Soc., 99, 7360-7362 (1977).

39) K. Atsumi and I. Kuwajima, "Selective Preparation of 1,3-Bis(trimethylsilyl)-1-, -2-propenyl, and 3-Trimethylsilyl-1,2-propadienyl Functional Groups", Tetrahedron Lett., 2001-2004 (1977).

40) I. Kuwajima, M. Kato, and T. Sato, "Efficient Method for the Preparation of Trimethylsilyl Enol Ethers of Acyltrimethylsilanes", J. Chem. Soc., Chem. Commun., 478-479 (1978).

41) T. Sato, T. Abe, and I. Kuwajima, "A New Rearrangement Reaction of 2-Chloro-1-trimethylsilyl Alkoxide. Preparation of $\beta$-Hydroxyalkyl- and $\beta$-Ketoalkyltrimethylsilane", Tetrahedron Lett., 259-262 (1978).

42) I. Kuwajima and M. Shimizu, "Oxidation of Olefins with Diphenyl Diselenide/Bromine/Hexamethyldistannoxane. A One-Step Preparation of $\alpha$-Phenylseleno Carbonyl Compounds from Olefins", Tetrahedron Lett., 1277-1280 (1978).

43) E. Nakamura, K. Hashimoto, and I. Kuwajima, "Highly Stereoselective Formation of Enol Silyl Ethers", Tetrahedron Lett., 2079-2082 (1978).

44) I. Kuwajima, T. Inoue, and T. Sato, "Dual Roles of Trimethylsilyl Group for Specific Generation of Enolates from $\beta$-Ketoalkyltrimethylsilanes. Regiospecific Preparation of Two Types of Acyclic Aldols", Tetrahedron Lett., 4887-4890 (1978).

45) I. Kuwajima, T. Abe, and K. Atsumi, "Reductive Silylation Reactions of Sulfides. A Facile Conversion of Carbon-Sulfur Linkages into Carbon-Silicon Ones", Chem. Lett., 383-386 (1978).

46) K. Atsumi and I. Kuwajima, "A New Ring Opening Reaction of Furaldehyde Diphenyldithioacetal via Reductive Silylation. Preparation of 2,3,4-Tris(trimethylsilyl)-3-alkenyl and 3,4,4-Tris(trimethylsilyl)-2-butenyl Ketones", Chem. Lett., 387-390 (1978).

47) I. Kuwajima and T. Abe, "A Simple Preparative Method of Alkylthiotrimethylsilanes", Bull. Chem. Soc. Jpn., 51, 2183-2184 (1978).

48) N. Minami, T. Abe, and I. Kuwajima, "Preparation of $\alpha, \beta$-Unsaturated Acyltrimethylsilanes", $J$. Organomet. Chem., 145, C1-3 (1978).

49) I. Kuwajima, I. Azegami, and E. Nakamura,"A Facile Method for the Preparation of 5-Alkoxy1,4-diketones", Chem. Lett., 1431-1434 (1978).

50) I. Kuwajima, T. Abe, N. Minami, and T. Sato, "A Remarkable Solvent Effect on the Reductive Silylation Reaction of Carboxylic Esters. Preparation of 1,1-Bis(trimethylsilyl)-1-alkanols", Bull. Chem. Soc. Jpn., 51, 2391-2393 (1978).

51) K. Atsumi and I. Kuwajima, "A Facile Ring Opening Reaction of Furfuryl Carbanion. Regioselective Generation of Di- or Trianionic Enolates", J. Am. Chem. Soc., 101, 2208-2210 (1979).

52) I. Kuwajima, K. Matsumoto, and T. Inoue, "Efficient Method for the Preparation of $\alpha$-Trimethylsilyl carboxylic Acid Esters", Chem. Lett., 41-42 (1979).

53) M. Shimizu, R. Takeda, and I. Kuwajima, "Regioselective Oxidation of Olefins into $\alpha$-Phenylseleno Ketones", Tetrahedron Lett., 419-422 (1979).

54) I. Kuwajima and I. Azegami, "Lewis acid Catalyzed Ring Opening Reaction of Cyclobutane- 
1,2-diols Having 1-Alkoxy Substituents. Selective Synthesis of $\alpha, \alpha$-Disubstituted $\beta$-Hydroxy cyclopentanones", Tetrahedron Lett., 2369-2372 (1979).

55) I. Kuwajima, T. Tanaka, and K. Atsumi, "Preparation and Reactions of 2-Substituted 3-Trimethylsilyl-4-en-1-one System", Chem. Lett., 779-782 (1979).

56) I. Kuwajima and M. Kato, "1-Trimethylsilylallylic Alcohols as Homoenolate Precursors. Stereoand Regiospecific Synthesis of Silyl Enol Ethers", J. Chem. Soc., Chem. Commun., 708-709 (1979).

57) M. Shimizu and I. Kuwajima, "Highly Efficient Method for Oxidation of Alcohols with tert-Butyl Hydroperoxide Catalyzed by Diaryl Diselenide", Tetrahedron Lett., 2801-2804 (1979).

58) M. Shimizu, R. Takeda, and I. Kuwajima, "Highly Selective anti-Markownikoff Type Oxidation of Olefinic Bonds of Allylic Alcohol Derivatives. Specific Synthesis of $\beta$-Alkoxy a-Phenylseleno Carbonyl Compounds", Tetrahedron Lett., 3461-3464 (1979).

59) I. Kuwajima, K. Atsumi, T. Tanaka, and T. Inoue, "Reaction of Furyllithium with Acyltrimethylsilanes, Specific Generation of 5-Trimethylsiloxy-3,4-pentadienone Enolates", Chem. Lett., 1239-1240 (1979).

60) I. Kuwajima and K. Matsumoto, " $\alpha$-Chloroacyltrimethylsilanes as $\alpha$-Trimethylsilylacyl Equivalents. Specific C-Acylation of Enolates", Tetrahedron Lett., 4095-4098 (1979).

61) T. Inoue and I. Kuwajima, "Highly Efficient Method for the Synthesis of Showdomycin", $J$. Chem. Soc., Chem. Commun., 251-253 (1980).

62) I. Kuwajima and M. Kato, "Base-Induced Rearrangement of 1-Trimethylsilylpropargyl Alcohol. Generation of Lithiated Trimethylsiloxyallenes and their Reactions", Tetrahedron Lett., 21, 623-626 (1980).

63) I. Kuwajima, K. Matsumoto, and S. Sugahara, "Reactions of Enolates of Acyltrimethylsilanes with Aldehydes. Cannizzaro Type Oxidation-Reduction Reaction of a Trimethylsilylcarbonyl Group", Chem. Lett., 525-528 (1980).

64) I. Kuwajima, M. Kato, and A. Mori, "Stereo- and Regioselective Conversion of 1-Trimethylsilylallylic Alcohols into the Silyl Enol Ethers Catalyzed by Butyllithium", Tetrahedron Lett., 21, 2745-2748 (1980).

65) M. Shimizu and I. Kuwajima, "Aryl Vinyl Selenoxides as a Versatile Reagent for Transfer of an Ethylene Unit to Enolates. New Synthetic Method of Formation of Cyclopropyl Ketones", $J$. Org. Chem., 45, 292-29231 (1980).

66) I. Kuwajima, S. Hoshino, T. Tanaka, and M. Shimizu, "A Facile Ring Opening Reaction of Furfuryl Selenides. Highly Efficient Method for Dienones", Tetrahedron Lett., 21, 3209-3212 (1980).

67) I. Kuwajima, A. Mori, and M. Kato, "Conversion of Carbon-Sulfur Linkages into CarbonSilicon Ones via Reductive Silylation. Preparation of Silyl Enol Ethers of Acyltrimethylsilanes", Bull. Chem. Soc. Jpn., 53, 2634-2638 (1980).

68) M. Shimizu and I. Kuwajima, "3-Phenylseleno-2-propenal as a Versatile Unit for the Oxetane Ring Formation", J. Org. Chem., 45, 4063-4065 (1980).

69) I. Kuwajima, M. Kato, and A. Mori, "Stereo- and Regio-controlled Aldol Synthesis", Tetrahedron Lett., 21, 4291-4294 (1980).

70) E. Nakamura, K. Hashimoto, and I. Kuwajima, "Silylation of Relatively Acidic Compounds with 
Alkyl Trimethylsilylacetate", Bull. Chem. Soc. Jpn., 54, 805-808 (1981).

71) M. Shimizu, H. Urabe, and I. Kuwajima, "Selective Oxidation of Hydroxy Group of Alcohols Having Phenylthio and Phenylseleno Groups", Tetrahedron Lett., 22, 2183-2186 (1981).

72) I. Kuwajima and R. Takeda, "Preparation of $\alpha$-Trialkylsilyl Ketones from Phenylseleno Derivatives via their Enol Silyl Ethers", Tetrahedron Lett., 22, 2381-2384 (1981).

73) M. Shimizu and I. Kuwajima, "One-Step Oxidation of Olefins into $\alpha$-Phenylseleno Carbonyl Compounds", Bull. Chem. Soc. Jpn., 54, 3100-3105 (1981).

74) M. Shimizu, R. Takeda, and I. Kuwajima, "Oxidation of Olefins into $\alpha$-Phenylseleno Carbonyl Compounds. Highly Regioselective anti-Markownikoff Type Oxidation of Allylic Alcohol Derivatives", Bull. Chem. Soc. Jpn., 54, 3510-3517 (1981).

75) I. Kuwajima and H. Urabe, "Regioselective Synthesis of $\Delta^{3}$-Butenolides via Oxidation of 2-Trimethylsilylfurans", Tetrahedron Lett., 22, 5191-5194 (1981).

76) M. Shimizu, R. Ando, and I. Kuwajima, "Highly Efficient Method for Ethylenic and Acetylenic Ketones via Fragmentation of Hydroxy Vinyl Selenones", J. Org. Chem., 46, 5246-5248 (1981).

77) I. Kuwajima, M. Shimizu, and H. Urabe, "Oxidation of Alcohols with tert-Butyl Hydroperoxide and Diaryl Diselenide", J. Org. Chem., 47, 837-842 (1982).

78) I. Kuwajima, E. Nakamura, and M. Shimizu, "Fluoride Mediated Reactions of Enol Silyl Ethers. Regiospecific Monoalkylation of Ketones", J. Am. Chem. Soc., 104, 1025-1030 (1982).

79) Y. S. Yokoyama, M. R. H. Elmoghayar, and I. Kuwajima, "Regiochemical Aspects in the Reactions of 2,3,5-Tri-O-benzoyl-D-ribofuranosyl Acetate with Silyl Enol Ethers Catalyzed by Stannic Chloride", Tetrahedron Lett., 23, 2673-2676 (1982).

80) I. Kuwajima and H. Urabe, "Regioselective Arylation of Silyl Enol Ethers of Methyl Ketones with Aryl Bromides", J. Am. Chem. Soc., 104, 6831-6833 (1982).

81) E. Nakamura and I. Kuwajima, "Isolation and Reactions of Titanium Homoenolates of Esters", $J$. Am. Chem. Soc., 105, 651-652 (1983).

82) I. Kuwajima, E. Nakamura, and K. Hashimoto, "Fluoride Catalyzed Reaction of Silylacetylenes with Carbonyl Compounds", Tetrahedron, 39, 975-982 (1983).

83) E. Nakamura and I. Kuwajima, "Formation of $\alpha$-Trichlorostannyl Ketones in the Reaction of Stannic Chloride with Enol Silyl Ethers", Chem. Lett., 59-62 (1983).

84) I. Kuwajima and E. Nakamura, "Silylation of Ketones with Ethyl Trimethylsilylacetate: (Z)-3-Tri-methylsiloxypentene", Org. Syn., 61, 122-129 (1983).

85) I. Kuwajima, S. Sugahara, and J. Enda, "Isomerization of 1-Trimethylsilylallenyl Ether to 1-Trimethylsilylpropargyl Ether. Preparation of 1-Methoxy-1-alken-3-ynes and 2-Methoxy-2,5dihydrofurans", Tetrahedron Lett., 24, 1061-1064 (1983).

86) E. Nakamura, J. Shimada, and I. Kuwajima, "Ring Expansion of Succinoin Derivatives. New Synthetic Routes to Cyclopentenones", J. Chem. Soc., Chem. Commun., 498-499 (1983).

87) E. Nakamura, K. Fukuzaki, and I. Kuwajima, "Cyclopentenones by Internal Acylation of Vinylsilanes. Rapid Construction of Trichotecane Type Carbon Frameworks", J. Chem. Soc., Chem. Commun., 499-501 (1983).

88) E. Nakamura, J. Shimada, Y. Horiguchi, and I. Kuwajima, "Formation and Characterization of Trichlorotitanium Enolates", Tetrahedron Lett., 24, 3341-3342 (1983).

89) E. Nakamura, M. Shimizu, I. Kuwajima, J. Sakata, K. Yokoyama, and R. Noyori, "Fluoride Catalyzed Aldol Reaction between Enol Silyl Ethers and Carbonyl Compounds", J. Org. Chem., 
48, 932-945 (1983).

90) E. Nakamura and I. Kuwajima, "Aldol Reactions of Trichlorotitanium Enolates. Revaluation of the Boat Transition State", Tetrahedron Lett., 24, 3343-3346 (1983).

91) E. Nakamura and I. Kuwajima, "Erythro Selective Aldol Reaction of $\alpha$-Stannyl Ketones", Tetrahedron Lett., 24, 3347-3350 (1983).

92) E. Nakamura, Y. Horiguchi, J. Shimada, and I. Kuwajima, "Remarkable Equatorial Selectivity in the Aldol Coupling between Enol Silyl Ethers and Cyclohexanone Acetals", J. Chem. Soc., Chem. Commun., 796-797 (1983).

93) H. Urabe, Y. Takano, and I. Kuwajima, "Chemoselective Desilylation of Silyl Enol Ethers with Tributyltin Fluoride Catalyzed by a Palladium", J. Am. Chem. Soc., 105, 5703-5704 (1983).

94) H. Urabe and I. Kuwajima, "Hydroxy Group Assisted Isomerization and Alkylation of Allylsilanes in Basic Media. $\alpha$-(1-Trimethylsilylallyl) Ketone as an $\alpha$-Alkenyl Ketone Equivalent", Tetrahedron Lett., 24, 4241-4244 (1983).

95) I. Kuwajima, R. Ando, and T. Sugawara, "Regio- and Site-selective Activation of CarbonCarbon Double Bonds to Nucleophilic Reagents. Cyclopropanation of Vinyl Selenones with Active Methylene Compounds", Tetrahedron Lett., 24, 4429-4432 (1983).

96) H. Urabe and I. Kuwajima, "Generation of Stannyl Derivatives of Methyl Ketones via a Selective Silyl/Stannyl Exchange and its Application to Aldol Reactions", Tetrahedron Lett., 24, 5001-5004 (1983).

97) R. Ando, T. Sugawara, and I. Kuwajima, "Reactions of Active Methyne Compounds with Vinyl Selenones. One-Step Synthesis of 2-Acylcyclopropanecarbaldehydes", J. Chem. Soc., Chem. Commun., 1514-1515 (1983).

98) H. Urabe and I. Kuwajima, "A Cyclopentanone Annulation via Intramolecular Acylation of Alkylsilanes", J. Org. Chem., 49, 1140-1141 (1984).

99) J. Shimada, K. Hashimoto, B. H. Kim, E. Nakamura, and I. Kuwajima, "Ring Expansion and Cleavage of Succinoin Derivatives. Geminal Acylation, Reductive Succinoylation, and Stereoselective Spiro Annelation Methods", J. Am. Chem. Soc., 106, 1759-1773 (1984).

100) M. Kato, A. Mori, H. Oshino, J. Enda, K. Kobayashi, and I. Kuwajima, "Base-Induced Rearrangement of 1-(Trimethylsilyl)allylic Alcohols. Stereo- and Regioselective Synthesis of Silyl Enol Ethers through Lithium Homoenolates", J. Am. Chem. Soc., 106, 1773-1778 (1984).

101) Y. S. Yokoyama, T. Inoue, and I. Kuwajima, "Reactions of 2,3,5-Tri-O-benzoyl-D-ribofuranosyl Acetate with Enol Silyl Ethers Catalyzed by Tin(IV) Chloride. Regiochemical Features", Bull. Chem. Soc. Jpn., 57, 553-556 (1984).

102) M. Kato and I. Kuwajima, "Specific Generation of Lithiated 3-Trimethylsiloxy-1,2-propadiene Derivatives from 1-(Trimethylsilyl)propargyl Alcohols", Bull. Chem. Soc. Jpn., 57, 827-830 (1984).

103) T. Sato, K. Matsumoto, T. Abe, and I. Kuwajima, "Reactions of 2-Chloroacyltrimethylsilanes with Grignard Reagents. Preparation of 3-(Trimethylsilyl)-2-alkanones and 2-(Trimethylsilyl)alkanols", Bull. Chem. Soc. Jpn., 57, 2167-2170 (1984).

104) M. Shimizu, R. Ando, and I. Kuwajima, "Reactions of 3-Hydroxy Vinyl Selenones with Alkoxides. Oxetane Formation and Fragmentation Reactions", J. Org. Chem., 49, 1230-1238 (1984).

105) E. Nakamura and I. Kuwajima, "Copper Catalyzed Acylation and Conjugate Addition of Zinc 
Homoenolate. Synthesis of 4- and 6-Oxo Esters", J. Am. Chem. Soc., 106, 3368-3370 (1984).

106) K. Fukuzaki, E. Nakamura, and I. Kuwajima, "Stereoselective Synthesis of trans-Hydrindanone by Internal Vinylsilane Acylation", Tetrahedron Lett., 25, 3591-3594 (1984).

107) R. Ando, T. Sugawara, M. Shimizu, and I. Kuwajima, "Reactions of Enolates with Vinyl Selenoxides and Vinyl Selenones. One-Step Synthesis of Cyclopropylcarbonyl Compounds", Bull. Chem. Soc. Jpn., 57, 2897-2904 (1984).

108) J. Enda, T. Matsutani, and I. Kuwajima, "Stoichiometric Generation of Magnesium Homoenolates from Acyltrimethylsilanes. Synthesis of 1,6-Diketone Derivatives", Tetrahedron Lett., 25, 5307-5310 (1984).

109) T. Inoue, T. Sato, and I. Kuwajima, "Aldol Reactions with $\alpha$-Trimethylsilyl Ketones. Dual Roles of Trimethylsilyl Group for Regiospecific Generation of Enolate Equivalents", J. Org. Chem., 49, 4671-4674 (1984).

110) J. Enda and I. Kuwajima, "A Lewis Acid Mediated Rearrangement Reaction of 1-(Trimethylsilyl)-prop-2-ynyl Trimethylsilyl Ethers to 2-Trimethylsilyl Enones", J. Chem. Soc., Chem. Commun., 1589 (1984).

111) I. Kuwajima, "Synthetic Organic Reactions by Means of Reactive Nucleophiles Generated through a Rearrangement of Silyl Group", J. Organomet. Chem., 286, 137-148 (1985).

112) E. Nakamura, J. Shimada, and I. Kuwajima, "A Ring Opening Reaction of 1-Siloxy-1-alkoxycyclopropanes. Preparation of Main Group Metal Homoenolate of Alkyl Propionate", Organometallics, 4, 641-646 (1985).

113) T. Sugawara and I. Kuwajima, "A One-Carbon Ring Enlarged Cyclopropanation or Vinylation of Cyclic Keto Esters and Sulfones", Tetrahedron Lett., 26, 5571-5574 (1985).

114) I. Kuwajima and E. Nakamura, "Reactive Enolates from Enol Silyl Ethers", Acc. Chem. Res., 18, 181-187 (1985).

115) Y. Takano, A. Yasuda, H. Urabe, and I. Kuwajima, "A Highly Efficient Method for Introduction of Butenolide Moieties to Various Electrophiles", Tetrahedron Lett., 26, 6225-6228 (1985).

116) H. Oshino, E. Nakamura, and I. Kuwajima, "Catalytic Homo-Reformatsky Reaction. Ambident Reactivities of Zinc Homoenolate of Propionate", J. Org. Chem., 50, 2802-2804 (1985).

117) E. Nakamura and I. Kuwajima, "Stereocontrolled Construction of Oxygenated Steroidal Side Chains. Synthesis and Stereochemistry of Depresosterol", J. Am. Chem. Soc., 107, 2138-2141 (1985).

118) J. Enda and I. Kuwajima, "General Method for Generation of 3-Siloxyallylmetallic species and their Synthetic Application", J. Am. Chem. Soc., 107, 5495-5501 (1985).

119) E. Nakamura, H. Oshino, and I. Kuwajima, "Trichlorotitanium and Alkoxytitanium Homoenolates. Preparation, Characterization, and Utilization for Organic Synthesis", J. Am. Chem. Soc., 108, 3745-3755 (1986).

120) Y. Hatanaka and I. Kuwajima, "Reactions of 3-[(Trimethylsilyl)methyl]cyclo-2-hexenone with Carbonyl Compounds. Regio- and Chemoselective Condensation", J. Org. Chem., 51, 1932-1934 (1986).

121) Y. Horiguchi, E. Nakamura, and I. Kuwajima, "Total Synthesis of $( \pm)$-Cortisone. Double Hydroxylation Reactions for Construction of Corticoid Side Chain", J. Org. Chem., 51, 4323-4325 (1986).

122) E. Nakamura and I. Kuwajima, "Palladium Catalyzed Reaction of Propionates. Arylation, 
Vinylation, and Acylation", Tetrahedron Lett., 27, 83-86 (1986).

123) Y. Hatanaka and I. Kuwajima, "An Intramolecular Acylation of Olefins Directed by Trimethylsilyl Group. Synthesis of 2-Cyclopropylcycloalkanones", Tetrahedron Lett., 27, 719-722 (1986).

124) H. Urabe and I. Kuwajima, "A Radical Cyclization between Enol Silyl Ethers and Aryl or Vinyl Bromides", Tetrahedron Lett., 27, 1355-1358 (1986).

125) Y. Horiguchi, S. Matsuzawa, E. Nakamura, and I. Kuwajima, "Me ${ }_{3} \mathrm{SiCl} / \mathrm{HMPA}$ Accelerated Conjugate Addition of Catalytic Copper Reagent. Stereoselective Synthesis of Enol Silyl Ethers of Aldehydes", Tetrahedron Lett., 27, 4025-4028 (1986).

126) E. Nakamura, S. Matsuzawa, Y. Horiguchi, and I. Kuwajima, " $\mathrm{Me}_{3} \mathrm{SiCl} / \mathrm{HMPA}$ Accelerated Conjugate Addition of Stoichiometric Organocopper Reagents", Tetrahedron Lett., 27, 4029-4032 (1986).

127) E. Nakamura, K. Sekiya, and I. Kuwajima, "Chiral Zinc Homoenolate of Methyl Isobutyrate. A New Building Block for the Synthesis of Chiral $\alpha$-Methylester", Tetrahedron Lett., 28, 337-340 (1987).

128) K. Tanino, Y. Hatanaka, and I. Kuwajima, "Directing Effect of a Silyl Group on Cationic Rearrangement Reactions", Chem. Lett., 385-388 (1987).

129) R. Matsuoka, Y. Horiguchi, and I. Kuwajima, "Stoichiometric Generation of 3-Siloxyallenyllithium and its Reaction with Electrophiles", Tetrahedron Lett., 28, 1299-1302 (1987).

130) E. Nakamura, S. Aoki, K. Sekiya, H. Oshino, and I. Kuwajima, "Carbon-Carbon Bond Forming Reactions of Zinc Homoenolate of Esters. A Novel Three-Carbon Nucleophile with General Synthetic Utility", J. Am. Chem. Soc., 109, 8056-8066 (1987).

131) K. Takanishi, H. Urabe, and I. Kuwajima, "Remarkable Stabilizing Effects of Silyl Group on Furfuryl Chlorides and Furfuryl Grignard Reagents", Tetrahedron Lett., 28, 2281-2282 (1987).

132) H. Sakata and I. Kuwajima, "Conjugate Addition of Organocopper Reagents to Unsaturated Esters", Tetrahedron Lett., 28, 5719-5722 (1987).

133) E. Nakamura and I. Kuwajima, "Ring Expansion and Cleavage of Succinoin Derivatives: Spiro[4.5]decane-1,3-dione and Ethyl 4-Cyclohexyl-4-oxobutanoate", Org. Syn., 65, 17-25 (1987).

134) T. Oshima, N. Hamazaki, M. Senshu, K. Kakinuma, and I. Kuwajima, "A New Naturally Occurring Polyamine Containing a Quaternary Ammonium Nitrogen", J. Biol. Chem., 262, 11979-11981 (1987).

135) S. Aoki, T. Fujimura, E. Nakamura, and I. Kuwajima, "Palladium-Catalyzed Arylation of Siloxycyclopropanes with Aryl Triflates. Carbon Chain Elongation via Catalytic Carbon-Carbon Bond Cleavage", J. Am. Chem. Soc., 110, 3296-3298 (1988).

136) S. Aoki, E. Nakamura, and I. Kuwajima, "Synthesis of 4-Keto Pimelates by PalladiumCatalyzed Carbonylative Symmetrical Coupling of Siloxycyclopropanes", Tetrahedron Lett., 29, 1541-1542 (1988).

137) K. Tanino, T. Katoh, and I. Kuwajima, "A Highly Selective One-Carbon Ring Enlargement Reaction Directed by Silicon", Tetrahedron Lett., 29, 1815-1818 (1988).

138) T. Katoh, K. Tanino, and I. Kuwajima, "A Highly Efficient Method for One-Carbon Ring Expansion. Preparation of 1-Alkoxy-2-methylenecycloalkanes", Tetrahedron Lett., 29, 1819-1822 (1988). 
139) E. Nakamura, S. Yamago, D. Matii, and I. Kuwajima, "Stereochemistry of the Fluoride Catalyzed Aldol Reaction of Enol Silyl Ethers. Evidence for Another Non-Chelate Transition State", Tetrahedron Lett., 29, 2207-2210 (1988).

140) I. Kuwajima, "1-Alkoxy-1-siloxycyclopropanes as Homoenolate Nucleophiles of Esters", Pure Appl. Chem., 60, 115-122 (1988).

141) E. Nakamura and I. Kuwajima, "Copper-Catalyzed Conjugate Addition of a Zinc Homoenolate: Ethyl 3-[3-(Trimethylsiloxy)cyclohex-2-enyl]]propionate", Org. Syn., 66, 43-49 (1988).

142) I. Kuwajima and H. Urabe, "Cyclopentanones from Carboxylic Acids via Intramolecular Acyl-ation of Alkylsilanes: 2-Methyl-2-vinylcyclopentanone", Org. Syn., 66, 87-94 (1988).

143) S. Matsuzawa, Y. Horiguchi, E. Nakamura, and I. Kuwajima, "Chlorosilane-Accelerated Conjugate Addition of Catalytic and Stoichiometric Organocopper Reagents", Tetrahedron, 45, 349-362 (1989).

144) S. Matsuzawa, M. Isaka, E. Nakamura, and I. Kuwajima, "Me ${ }_{3} \mathrm{SiCl}$-Assisted 1,2-Addition of Organocuprates to Carbonyl Compounds", Tetrahedron Lett., 30, 1975-1978 (1989).

145) Y. Horiguchi, E. Nakamura, and I. Kuwajima, "Double Hydroxylation of Enol Silyl Ethers. A Single-Step Synthesis of $\alpha, \alpha^{\prime}$-Dihydroxy Ketones", Tetrahedron Lett., 30, 3323-3326 (1989).

146) Y. Horiguchi, Y. Kataoka, and I. Kuwajima, "Regioselective Synthesis of Two Types of Cyclic 3-(Trimethylsilylmethyl)enones", Tetrahedron Lett., 30, 3327-3330 (1989).

147) Y. Horiguchi, E. Nakamura, and I. Kuwajima, "Total Synthesis of $( \pm)$-Cortisone. Double Hydroxylation Reaction for Corticoid Synthesis", J. Am. Chem. Soc., 111, 6257-6265 (1989).

148) T. Matsuda, K. Tanino, and I. Kuwajima, "A Selective One-Carbon Ring Expansion Reaction of 1-Siloxycycloalkanecarbaldehydes Catalyzed by a Lewis Acid", Tetrahedron Lett., 30, 4267-4270 (1989).

149) K. Tanino, K. Sato, and I. Kuwajima, "Silicon-Based Nucleophiles Mediated One-Carbon Ring Enlargement Reactions of 1-(Trimethylsilylmethyl)cycloalkanecarbaldehydes", Tetrahedron Lett., 30, 6551-6554 (1989).

150) Y. Horiguchi, T. Furukawa, and I. Kuwajima, "A Highly Efficient Eight-Membered Ring Cyclization for Construction of Taxane Carbon Framework", J. Am. Chem. Soc., 111, 8277-8279 (1989).

151) S. Aoki, T. Fujimura, E. Nakamura, and I. Kuwajima, "Palladium- and Platinum-Catalyzed Reaction of Siloxycyclopropanes with Acid Chlorides. A Homoenolate Route to 1,4-Dicarbonyl Compouds", Tetrahedron Lett., 30, 6541-6544 (1989).

152) Y. Horiguchi, M. Komatsu, and I. Kuwajima, "Does $\mathrm{Me}_{3} \mathrm{SiCl}$ Activate Conjugate Addition of Copper Reagents as a Lewis Acid ?", Tetrahedron Lett., 30, 7087-7090 (1989).

153) H. Sakata, Y. Aoki, and I. Kuwajima, "A Remarkable Catalytic Effect of Cu(II) Species for Conjugate Addition of Grignard Reagents to $\alpha, \beta$-Unsaturated Esters", Tetrahedron Lett., 31, 1161-1164 (1990).

154) K. Tanino, T. Nakamura, and I. Kuwajima, "Highly Threo-Selective Ene-Reaction of 2-(Alkyl-thio)allyl Silyl Ethers with Aldehydes", Tetrahedron Lett., 31, 2165-2168 (1990).

155) T. Kato, S. Marumoto, T. Sato, and I. Kuwajima, "A Remarkable Effect of a 3-OLi group to Fix the Conformation of Lithium 1-Phenyl-1-propanides", Synlett, 671-672 (1990).

156) Y. Aoki and I. Kuwajima, "A Catalytic Role of $\mathrm{Cu}(\mathrm{II})$ for Conjugate Addition of Grignard Reagents. A Completely Different Behavior from Organocuprates", Tetrahedron Lett., 31, 
7457-7460 (1990).

157) M. Komatsu, I. Suehiro, Y. Horiguchi, and I. Kuwajima, "[3 + 2] Cycloaddition of 2-Alkoxycyclopropyl Carbonyl Compounds with Enol Silyl Ethers for Functionalized Cyclopentane Formation", Synlett, 771-773 (1991).

158) P. G. Williard, E. Nakamura, and I. Kuwajima, "Structure of (2R,1'S*)-2-(Hydroxyphenylmethyl)-2-methylcyclohexane, $\mathrm{C}_{14} \mathrm{H}_{18} \mathrm{O}_{2}$ ", Acta Cryst., C47, 984-985 (1991).

159) Y. Sakai, Y. Kojima, Y. Ohashi, K. Morihira, T. Furukawa, Y. Horiguchi, and I. Kuwajima, "Structure of endo-(5R*,6R*,11R*,12S*)-5,5,11,12-Tetrahydro-4,11,12-trimethoxy-9,13,13trimethyl-5-(triethylsiloxy)-6,10-methano-8(7H)-benzocyclodecenone", Acta Cryst., C47, 2700-2702 (1991).

160) K. Tanino, H. Shoda, T. Nakamura, and I. Kuwajima, "Ene Reaction of 2-(Alkylthio)allyl Silyl Ether Involving a Chirality Transfer", Tetrahedron Lett., 33, 1337-1340 (1992).

161) T. Kanbara, T. Kushida, N. Saito, I. Kuwajima, K. Kubota, and T. Yamamoto, "Preparation and Properties of Highly Electron-accepting Poly(pyrimidine-2,5-diyl)", Chem. Lett., 583-586 (1992).

162) S. Marumoto and I. Kuwajima, "Regio- and Stereo-defined Synthesis of Organosilicon Compounds via Rearrangement of Silyl Group", Chem. Lett., 1421-1424 (1992).

163) T. Nakamura, K. Tanino, and I. Kuwajima, "Remarkable Stereochemical Features of Ene Reaction of 2-(Alkylthio)crotyl Silyl Ethers. Proposal of a Six-Membered Chair-like Transition State", Chem. Lett., 1425-1428 (1992).

164) Y. Kataoka, Y. Nakamura, K. Morihira, H. Arai, Y. Horiguchi, and I. Kuwajima, "Lewis Acid Mediated Intramolecular Cyclization of the Dienol Silyl Ether or Enol Silyl Ether and the Acetal for Medium-Sized Ring Formation", Tetrahedron Lett., 33, 6979-6982 (1992).

165) T. Furukawa, K. Morihira, Y. Horiguchi, and I. Kuwajima, "Synthetic Studies on Taxane Carbon Framework. A Highly Efficient Eight-Membered Ring Cyclization with Complete Stereocontrol", Tetrahedron, 48, 6975-6984 (1992).

166) K. Tanino, M. Takahashi, K. Murayama, and I. Kuwajima, "Generation of a Lewis Acid Activated Formaldimine and its Reactions with Enol Silyl Ethers. N-Unsubstituted Aminomethylation", J. Org. Chem., 57, 7009-7010 (1992).

167) K. Morihira, M. Seto, T. Furukawa, Y. Horiguchi, and I. Kuwajima, "The Seven-Membered Ring Intermediate to Control the Stereochemistry on the Eight-Membered Taxane B Ring Cyclization", Tetrahedron Lett., 34, 345-348 (1993).

168) M. Seto, K. Morihira, S. Katagiri, T. Furukawa, Y. Horiguchi, and I. Kuwajima, "Synthesis of C-Aromatic Taxinine Derivatives", Chem. Lett., 133-136 (1993).

169) T. Nakamura, K. Tanino, and I. Kuwajima, "Highly Stereoselective Chelation Controlled Ene Reaction of 2-(Alkylthio)allyl Silyl Ethers", Tetrahedron Lett., 34, 477-480 (1993).

170) Y. Kojima, Y. Ohashi, T. Osano, T. Matsuzaki, Y. Horiguchi, and I. Kuwajima, "Crystal Structure of (5RS, 6RS, 10RS, 11RS)-5,6,10,11-Tetrahydro-5-acetyl-8-formyl-10-hydroxy4,11-dimethoxy-7,7,9-trimethyl-6,10-methano-7H-benzocyclononene", Anal. Sci., 9, 433-434 (1993).

171) A. Adachi, K. Masuya, K.Tanino, and I. Kuwajima, "An Enantioselective Synthesis of Anthracycline Precursor", J. Org. Chem., 58, 4189-4190 (1993).

172) T. Furukawa, M. Seto, Y. Horiguchi, and I. Kuwajima, "Diastereoselective Conjugate Addition 
for Construction of Taxane Precursors", Chem. Lett., 1279-1282 (1993).

173) S. Kamei, A. Uchida, Y. Ohashi, M. Seto, K. Morihira, Y. Horiguchi, and I. Kuwajima, "Structure of endo-(5R*,6R*,10R*,11 $\left.\mathrm{S}^{*}\right)$-10-(tert-Butyldimethylsiloxy)-5,6,10,11-tetrahydro5-hydroxy-4,11-dimethoxy-7,7,9-trimethyl-6,10-methano-(7H)-benzocyclononene-8-carbaldehyde", Acta Cryst., C49, 1201-1203 (1993).

174) Y. Horiguchi, I. Suehiro, A. Sasaki, and I. Kuwajima, "Diastereoselective [3 + 2] Cycloaddition of Methyl 2-Phenylthiocyclopropyl Ketones with Enol Silyl Ethers: Synthesis of Functionalized Cyclopentanes", Tetrahedron Lett., 34, 6077-6080 (1993).

175) H. Shoda, T. Nakamura, K. Tanino, and I. Kuwajima, "Lewis Acid Promoted Ene-like Reactions of Enol Ethers with Aldehydes", Tetrahedron Lett., 34, 6281-6284 (1993).

176) S. Marumoto and I. Kuwajima, "Regiochemically and Stereochemically Defined Synthesis of Allylsilanes", J. Am. Chem. Soc., 115, 9021-9024 (1993).

177) M. Takahashi, K. Tanino, and I. Kuwajima, "Construction of N-Acylated 4-Piperidones via Selective Carbon-Nitrogen and Carbon-Carbon Bond Formation", Chem. Lett., 1655-1658 (1993).

178) S. Kamei, Y. Sasaki, Y. Ohashi, A. Adachi, K. Tanino, and I. Kuwajima, "Structure of an Optically Active Anthracycline Precursor", Acta Cryst., C49, 1509-1512 (1993).

179) S. Kamei, Y. Takenaka, Y. Sakai, Y. Ohashi, M. Seto, Y. Horiguchi, and I. Kuwajima, "Crystal Structure of Exo-(5R*,6R*,11S*,12S*)-5,6,11,12-tetrahydro-4,11,12-trimethoxy-9,13,13trimethyl-5-[(triethylsilyl)oxy]-6,10-methano-8(7H)-benzocyclodecenone", Anal. Sci., 9, 741-742 (1993).

180) S. Kamei, Y. Sakai, Y. Ohashi, K. Tsuruta, Y. Horiguchi, and I. Kuwajima, "Structure of endo$\left(5 \mathrm{~S}^{*}, 6 \mathrm{~S}^{*}, 11 \mathrm{R}^{*}, 12 \mathrm{R}^{*}\right)-5,6,11,12-\mathrm{Tetrahydro-5,6-dihydroxy-4,11,12-trimethoxy-9,13,13-trimethyl-}$ 6,10-methano-8(7H)-benzocyclodecenone", Acta Cryst., C49, 1802-1804 (1993).

181) M. Takayanagi, N. Umamori, K. Tanino, and I. Kuwajima, "A Novel Transformation Involving Selective Formation and Cleavage of C-C Bonds", J. Am. Chem. Soc., 115, 12635-12636 (1993).

182) S. Kamei, Y. Takenaka, A. Uchida, Y. Ohashi, T. Furukawa, Y. Horiguchi, and I. Kuwajima, "Crystal Structure of (1R*, 2R*, 6S*, 7S*, 9S*)-6,10,10,12-Tetramethyl-1-[(triisopropylsilyl)oxy]-tricyclo[7.3.1.02,7]tridec-11-ene-6,11-dicarbaldehydes", Anal. Sci., 9, 877-878 (1993).

183) Y. Takenaka, Y. Sakai, Y. Ohashi, T. Furukawa, Y. Horiguchi, and I. Kuwajima, "Crystal Structure of (5R*)-5-[(6S*)-2-(Dimethoxumethyl)-6-hydroxycyclohex-1-ene-1-yl]-methyl2,6,6-trimethyl-3-[(tri-isopropylsilyl)oxy]cyclohex-2-en-1-one", Anal. Sci., 9, 883-884 (1993).

184) S. Kamei, Y. Takenaka, Y. Sakai, Y. Ohashi, K. Tsuruta, Y. Horiguchi, and I. Kuwajima, "Crystal Structure of exo-(5R*)-5-[(1R*)-[2-(dimethoxymethyl)-6-methoxy phenyl]-[(trimethylsilyl)-oxy]methyl]-5-hydroxy-2,4,4-trimethyl-3-oxocyclohex-1-en-1-yl Pivaloate", Anal. Sci., 9, 889-890 (1993).

185) Y. Tohyama, K. Tanino, and I. Kuwajima, "Highly Stereoselective Ene Reaction of Aldimine with 2-(Alkylthio)allyl Silyl Ethers", J. Org. Chem., 59, 518-519 (1994).

186) M. Seto, K. Morihira, Y. Horiguchi, and I. Kuwajima, "An Efficient Approach toward Taxinine Analogues: Atrop- and Diastereoselective Eight-Membered B Ring Cyclization for Synthesis of C-Aromatic Taxinine Derivatives", J. Org. Chem, 59, 3165-3174 (1994).

187) Y. Takenaka, T. Ono, A. Uchida, Y. Ohashi, T. Furukawa, Y. Horiguchi, and I. Kuwajima, "endo-(1R*,9R*,10R*)-9,10-Dimethoxy-12,15,15-trimethyltricyclo[9.3.1.03,8]pentadeca-3(8),11- 
diene-4,13-dione", Acta Cryst., C50, 556-558 (1994).

188) T. Nakamura, N. Waizumimi, K. Tsuruta, Y. Horiguchi, and I. Kuwajima, "Synthesis of Taxol Analogues: Control of Atropisomerism", Synlett, 584 -586 (1994).

189) T. Nakamura, N. Waizumi, Y. Horiguchi, and I. Kuwajima, "An Enantioselective Synthesis of A-Ring fragment of Taxol", Tetrahedron Lett., 35, 7813-7816 (1994).

190) M. Seto, K. Sakurai, Y. Horiguchi, and I. Kuwajima, "Functional group Elaboration for Taxol C-Ring. $\gamma$-Enoliozation of the $\alpha, \beta$-Enone Directed by the Hydroxy Group", Synlett, 993-994 (1994).

191) K. Masuya, K. Tanino, and I. Kuwajima, "3-(Alkylthio)-1,2-Bissiloxy-3-butenes as Efficient Chirality Transferred Building Blocks", Tetrahedron Lett., 35, 7965-7968 (1994).

192) Y. Takenaka, S. Kubo, Y. Ohashi, T. Nakamura, N. Waizumi, Y. Horiguchi, and I. Kuwajima, "endo-(5R,6R,11S,12S)-5,6,11,12-Tetrahydro-6-hydroxy-4,11,12-trimethoxy-9,13,13-trimethyl5-[(trimethylsilyl)oxy]-6,10-methano-8(7H)-benzocyclodecenone", Acta Cryst., C50, 1820-1822 (1994).

193) M. Takayanagi, K. Tanino, and I. Kuwajima, "Conjugate Addition of Alkenylsulfides with $\alpha, \beta$-Unsaturated Carbonyl Compounds. Remarkable $n-\pi^{*}$ Orbital Interaction for Control of Regio- and Stereochemistry", Synlett, 173-174 (1995).

194) Y.Horiguchi, E. Nakamura, and I. Kuwajima, "Double Hydroxylation Reaction for Construction of the Corticoid Side Chain: Synthesis of 16-Methylcortexolone", Org. Syn., 73, 123 (1995).

195) K. Masuya, K. Domon, K. Tanino, and I. Kuwajima, "A New Synthetic Method for Cyclopentanones via Formal [3 + 2] Cycloaddition Reaction", Synlett, 157-158 (1996).

196) Y. Takahashi, K. Tanino, and I. Kuwajima, "Methylenecyclopentane Annulation via Formal [3 + 2] Cycloaddition Reactions", Tetrahedron Lett., 37, 5943-5946 (1996).

197) K. Sato, T. Koga, K. Masuya, K. Tanino, and Isao Kuwajima, "Diastereoselective Introduction of Carbon Chain to Pyrrolidone Derivatives", Synlett, 751-752 (1996).

198) R. Hara, T. Furukawa, Y. Horiguchi, and I. Kuwajima, "Total Synthesis of ( \pm )-Taxusin", J. Am. Chem. Soc., 118, 9186-9187 (1996).

199) I. Kuwajima, and K. Tanino, "New Aspects of Vinylsulfide Chemistry", J. Syn. Org. Chem. Jpn., 54, 929-940 (1996).

200) T. Nakamura, T. Matsui, K. Tanino, and I. Kuwajima, "A New Approach for Ingenol Synthesis", J. Org. Chem., 62, 3032-3033 (1997).

201) K. Tanino, Y. Yoshitani, F. Moriyama, and I. Kuwajima, "Control of Stereochemistry by $\sigma$-Participation of a Silyl Group. Novel Ring Expansion Reactions of a 1-Oxa-2-silacyclopentane Derivative", J. Org. Chem., 62, 4206-4207 (1997).

202) K. Domon, K. Masuya, K. Tanino, and I. Kuwajima," Highly Efficient Method for Coriolin Synthesis", Tetrahedron Lett., 38, 465-468 (1997).

203) M. Sugai, K. Tanino, and I. Kuwajima, "A New Synthetic Method for Cyclic Allenes and Acetylenes. Cleavage of a C-C Bond Directed by a Silyl Group", Synlett Special Issue, 461-462 (1997).

204) H. Kusama, T. Mori, I. Mitani, T. Kashima, and I. Kuwajima, "Diastereo- and Enantioselective Synthesis of Allylsilanes. A Useful C Ring Fragment of Taxol", Tetrahedron Lett., 38, 4129-1431 (1997).

205) K. Masuya, K. Domon, K. Tanino, and I. Kuwajima, "Highly Regio- and Stereoselective [3 + 2] 
Cyclopentanone Annulation Using a 3-(Alkylthio)-2-siloxyallyl Cationic Species", J. Am. Chem. Soc., 120, 1724-1731 (1998).

206) K. Tanino, T. Shimizu, M. Kuwahara, and I. Kuwajima, "A Novel Method for Inside Selective Silylation of 1,2-Diols", J. Org. Chem., 63, 2422-2424 (1998).

207) K. Morihira, T. Nishimori, H. Kusama, Y. Horiguchi, I. Kuwajima, and T. Tsuruo, "Synthesis of C-Ring Aromatic Taxoids and Evaluation of their Multi-Drug Resistance Reversing Activities", Bioorg. Med. Chem. Lett., 8, 2973-2976 (1998).

208) K. Morihira, T. Nishimori, H. Kusama, Y. Horiguchi, I. Kuwajima, and T. Tsuruo, "Synthesis and Evaluation of Artificial Taxoids with Antitumor and Multi-Drug Resistance Reversing Activities", Bioorg. Med. Chem. Lett., 8, 2977-2982 (1998).

209) K. Morihira, R. Hara, S. Kawahara, T. Nishimori, N. Nakamura, H. Kusama, and I. Kuwajima, "Enantioselective Total Synthesis of Taxol", J. Am. Chem. Soc., 120, 12980-12981 (1998).

210) H. Mizuno, K. Domon, K. Masuya, K. Tanino, and I. Kuwajima, "Total Synthesis of (-)-Coriolin", J. Org. Chem., 64, 2648-2656 (1999).

211) R. Hara, T. Furukawa, H. Kashima, H. Kusama, Y. Horiguchi, and I. Kuwajima, "Enantioselective Total Synthesis of (+)-Taxusin", J. Am. Chem. Soc., 121, 3072-3082 (1999).

212) H. Kusama, K. Morihira, T. Nishimori, T. Nakamura, and I. Kuwajima, "Cope Rearrangement of $\Delta^{3,8}$-Taxane Tricarbocycles: Remarkable Solvent Effect on Product Distribution", Tetrahedron Lett, 40, 4235-4238 (1999).

213) K. Masuya, K. Tanino, and I. Kuwajima, "A New Method for the Synthesis of Medium- and Large-Sized Carbocycles", Synlett, 647-649 (1999).

214) N. Watanabe, K. Tanino, and I. Kuwajima, "An Efficient Method for Bicyclic Enone Synthesis", Tetrahedron Lett., 40, 8133-8136 (1999).

215) H. Kusama, R. Hara, S. Kawahara, T. Nishimori, H. Kashima, N. Nakamura, K. Morihira, and I. Kuwajima, "Enantioselective Total Synthesis of (-)-Taxol", J. Am. Chem. Soc., 122, 3811-3820 (2000).

216) Y. Egami, M. Takayanagi, K. Tanino, and I. Kuwajima, "Regiocontrolled Ring Opening Reactions of a Cyclic Acetal, Heterocycles, 52, 583-586 (2000).

217) K. Tanino, T. Shimizu, M. Miyama, and I. Kuwajima, "A Novel [5 + 2] Cycloaddition Reaction Using a Dicobalt Acetylene Complex", J. Am. Chem. Soc., 122, 6116-6117 (2000).

218) T. Shimizu, K. Tanino, and I. Kuwajima, "An Intramolecular Hetero Diels-Alder Reaction of $\alpha$ (Alkynylsiloxy)aldimine Derivatives", Tetrahedron Lett., 41, 5715-5718 (2000).

219) I. Kuwajima and H. Kusama, "Synthetic Studies on Taxoids: Enantioselective Total Synthesis of (+)-Taxusin and (-)-Taxol", Synlett, 1385-1401 (2000).

220) D. Takano, T. Nagamitsu, H. Ui, K. Shiomi, Y. Yamaguchi, R. Masuma, I. Kuwajima, and S. Omura, "Absolute Configuration of Nafuredin, A New Specific NADH-Fumarate Reductase Inhibitor", Tetrahedron Lett., 42, 3017-3020 (2001).

221) D. Takano, T. Nagamitsu, H. Ui, K. Shiomi, Y. Yamaguchi, R. Masuma, I. Kuwajima, and S. Omura, "Total Synthesis of (+)-Nafuredin, A Selective NADH-Fumarate Reductase Inhibitor", Org. Lett., 3, 2289-2291 (2001).

222) T. Sunazuka, M. Handa, K. Nagai, T. Shirahata, Y. Harigaya, K. Otoguro, I. Kuwajima, and S. Omura, "The First Total Synthesis of ( \pm )-Arisugacin A, a Potent, Orally Bioavailable Inhibitor of Acetylcholine Esterase", Org. Lett., 4, 367-369 (2002). 
223) T. Hirose, T. Sunazuka, T. Shirahata, D. Yamamoto, Y. Harigaya, I. Kuwajima, and S. Omura, "Short Total Synthesis of (+)-Madindoline A and B", Org. Lett., 4, 501-503 (2002).

224) T. Sunazuka, T. Shirahata, K. Yoshida, D. Yamamoto, Y. Harigaya, T. Nagai, H. Kiyohara, H. Yamada, I. Kuwajima, and S. Omura, "Total Synthesis of Pinellic Acid, a Potent Oral Adjuvant for Nasal Influenza Vaccine. Determination of the Relative and Absolute Configuration", Tetrahedron Lett., 43 1265-1268 (2002).

225) K. Tanino, K. Ohnuki, K. Asano, M. Miyashita, T. Nakamura, Y. Takahashi, and I. Kuwajima, "Total Synthesis of Ingenol", J. Am. Chem. Soc., 125, 1498-1500 (2003).

226) T. Shirahata, T. Sunazuka, K. Yoshida, D. Yamamoto, Y. Harigaya, T. Nagai, H. Kiyohara, H. Yamada, I. Kuwajima, and S. Omura, "Total Synthesis and Adjuvant Activity of All Stereoisomers of Pinellic Acid", Bioorg. Med. Chem. Lett., 13, 937-941 (2003).

227) T. Nagamitsu, D. Takano, K. Shiomi, H. Ui, Y. Yamaguchi, R. Masuma, Y. Harigaya, I. Kuwajima, and S. Omura, "Total Synthesis of Nafuredin- $\gamma$, a $\gamma$-Lactone Related to Nafuredin with Selective Inhibitory Activity against NADH-fumarate Reductase", Tetrahedron Lett., 44, 6441-6444 (2003).

228) N. Arai, N. Chikaraishi, M. Ikawa, S. Omura, and I. Kuwajima, "Enantioselective Preparation of Asymmetrically Protected 2-Propanoyl-1,3-propanediol Derivatives: Toward the Total Synthesis of Kazusamycin A", Terahedron: Asymmetry, 15, 733-741 (2004).

229) T. Sunazuka, M. Honda, K. Nagai, T. Shirahata, Y. Harigaya, K. Otogura, I. Kuwajima, and S. Omura, "Absolute Stereochemistries and Total Synthesis of (+)-Arisugacins A and B, Potent, Orally Bioactive and Selective Inhibitors of Acetylcholinesterase”, Tetrahedron, 60, 7845-7859 (2004).

230) T. Nagamitsu, D. Takano, T. Fukuda, K. Otoguro, I. Kuwajima, Y. Harigaya, and S. Omura, “Total Synthesis of (-)-Borrelidin, Org. Lett., 6, 1865-1867 (2004).

231) N. Arai, N. Chikaraishi, S. Omura, and I. Kuwajima, "First Total Synthesis of Antitumor Compound (-)-Kazusamycin A and Absolute Structure Determination", Org. Lett., 6, 2845-2848 (2004).

232) T. Sunazuka, K. Yoshida, N. Kojima, T. Shirahata, T. Hirose, M. Honda, D. Yamamoto, Y. Harigaya, I. Kuwajima, and S. Omura, "Total Synthesis of (-)-Physovenine from (-)-3aHydroxyfuroindoline", Tetrahedron Lett., 46, 1459-1461 (2005).

233) S. Zhou, H. Chen, W. Liao, S.-H. Chen, G. Li, R. Ando, and I. Kuwajima, "A Practical Synthesis of (-)-Kazusamycin A", Tetrahedron Lett., 46, 6341-6344 (2005).

234) N. Arai, H. Ui, S. Omura, and I. Kuwajima, "Studies toward the Total Synthesis of GKK$1032 \mathrm{~A}_{2}$, a Structurally Unique Antitumor Compound: Stereoselective Construction of the Basic Carbon Skeleton", Synlett, 1691-1694 (2005).

235) T. Sunazuka, T. Shirahata, S. Tsuchiya, T. Hirose, R. Mori, Y. Harigaya, I. Kuwajima, and S. Omura, "A Concise Stereoselective Route to the Indoline Spiroaminal Framework of Neoxaline and Oxaline", Org. Lett., 7, 941-3 (2005).

236) I. Kuwajima and K. Tanino, “Total Synthesis of Ingenol”, Chem. Rev., 105, 4661-4670 (2005).

237) T. Hirose, T. Sunazuka, D. Yamamoto, N. Kojima, T. Shirahata, Y. Harigaya, I. Kuwajima, and S. Omura, "Determination of the Absolute Stereochemistry and Asymmetric Total Synthesis of Madindolines A and B: A Practical Improvement to a Second-Generation Approach from the First Generation", Tetrahedron, 61, 6015-6039 (2005). 
238) R. Ando, Y. Amano, H. Nakamura, N. Arai, and I. Kuwajima, "Design, Synthesis, and Evaluation of Novel Kazusamycin A Derivatives as Potent Antitumor Agents", Bioorg. Med. Chem. Lett, 16, 3315-3318 (2006).

239) T. Shirahata, T. Sunazuka, K. Yoshida, D. Yamamoto, Y. Harigaya, I. Kuwajima, T. Nagai, H. Kiyohara, H. Yamada, and S. Omura, "Total Synthesis, Elucidation of Absolute Stereochemistry and Adjuvant Activity of Trihydroxy Fatty Acids", Tetrahedron, 62, 9483-9496 (2006).

240) T. Nagamitsu, D. Takano, K. Marumoto, F. Fukuda, K. Otoguro, K. Takeda, I. Kuwajima, Y. Harigaya, and S. Omura, “Total Synthesis of Borrelidin”, J. Org. Chem., 72, 2744-2756 (2007). 